\title{
Transferring the critically ill patient: are we there yet?
}

\author{
Joep M Droogh ${ }^{1 *}$, Marije Smit ${ }^{1}$, Anthony R Absalom², Jack JM Ligtenberg ${ }^{3}$ and Jan G Zijlstra ${ }^{1}$
}

Abstract
During the past few decades the numbers of ICUs
and beds has increased significantly, but so too has
the demand for intensive care. Currently large, and
increasing, numbers of critically ill patients require
transfer between critical care units. Inter-unit transfer
poses significant risks to critically ill patients, particularly
those requiring multiple organ support. While the safety
and quality of inter-unit and hospital transfers appear to
have improved over the years, the effectiveness of
specific measures to improve safety have not been
confirmed by randomized controlled trials. It is generally
accepted that critically ill patients should be transferred
by specialized retrieval teams, but the composition,
training and assessment of these teams is still a matter
of debate. Since it is likely that the numbers and
complexity of these transfers will increase in the near
future, further studies are warranted.

\section{Introduction}

Since the establishment of the first ICUs in the 1950s, the demand for intensive care has grown exponentially. When demand exceeds supply, or when highly specialized care is required, transfer of critically ill patients becomes necessary. In the United Kingdom alone, more than 10,000 patients required secondary transfers in 1986 [1]. In the USA 1 in 20 patients requiring ICU care is transferred to another hospital [2]. Similar transfer rates probably occur elsewhere.

The number of transfers is likely to increase because of supply-demand imbalances. Recognition that centralization of specialist care is associated with reduced mortality rates might generate a new stream of transfers [2]. A recent study conducted in the USA suggested that the lives of

\footnotetext{
* Correspondence: j.m.droogh@umcg.nl

${ }^{1}$ Department of Critical Care, Research Program for Critical Care,

Anesthesiology, Per-operative and Emergency medicine (CAPE), University

Medical Center Groningen, University of Groningen, Hanzeplein 1, 9700 RB

Groningen, The Netherlands

Full list of author information is available at the end of the article
}

4,000 patients might have been saved in a year had they been transferred to another, better qualified hospital [3].

Interhospital transfers may save lives but they are expensive, logistically challenging, and risky. The transport process itself is associated with a risk of physiological deterioration and adverse events. The incidence of adverse events is proportional to the duration of the transfer, to the pre-transfer severity of illness or injury and to the inexperience of the medical escorts [4-6].

Since the late 1970s, safety concerns have motivated several studies of when, how and where to transfer critically ill patients. One of the first concluded that earlier transfer, resuscitation before transfer, continuing medical care during the journey, and hence a slower and smoother journey are beneficial to patients [7] and these conclusions apply to this day. In 1986 Ehrenwerth and colleagues [8] concluded that, with a specialized transport team and appropriate haemodynamic stabilization and monitoring, severely ill patients can be transported safely. From then on, the equipment improved, trolleys were modified and the first mobile ICU appeared [9].

Although transport guidelines appeared during the 1990s [10,11], a review published in 1999 still reported adverse events in up to $70 \%$ of transports. This led the authors to urge intensivists to follow guidelines concerning logistical organization, personnel, equipment and monitoring during transport [12]. Newer guidelines continued to emphasize the principles concerning personnel, organization and equipment [13-15]. Nonetheless, high rates of incidents continued to be published, many of which appeared to be avoidable, and associated with nonadherence to the guidelines [16-19].

In 2005, Haji-Michael [20] discussed two main reasons why, despite the existence of guidelines, interhospital transfer of the critically ill patient is still associated with avoidable mishaps. The first reason concerns sponsorship: those with responsibility and authority for the care of the patients are simply not the ones doing the transfers. The second reason is a lack of a motivation for change we have always somehow managed [20]. A third reason 
might be the lack of evidence that the recommendations are of benefit. The guidelines present clear recommendations but are based on weak evidence; cohort studies, case series, and expert opinion.

In this review we evaluate the current literature on the organization and safety of transfers of critically ill adult patients. We will also draw on the literature concerning paediatric intensive care transfers, since these have already been well organized for a long time.

\section{Research and quality management}

Transport of critically ill patients repeatedly illustrates Murphy's Law ('if anything can go wrong, it will'). Quality control studies and research into measures to improve safety depend strongly on accurate and reliable data. However, the reported incidence of adverse events varies from 3 to $75 \%[6,21]$, not only because of differences in incidences, but also because different definitions are used. For example, Philpot and colleagues [21] defined as incidents unintended extubation, difficult intubation, intravenous access loss, medication errors, pneumothorax and bag-valve ventilation required on arrival. Other studies also consider blown equipment fuses or transport delays to be incidents [22,23]. These different definitions make it difficult to compare incident rates.

Another problem is that it is sometimes difficult to attribute adverse events to the transport process itself due to poorly documented pre-transport variables and posttransport management differences. Furthermore, many studies only examined short-term adverse events, although it cannot be ruled out that transport-related adverse events can occur later on [24]. Incident reports with standardized definitions are of major importance for quality management as well as for research purposes.

Risk scores are used to quantify severity of illness, estimate mortality risks, and for benchmarking of ICUs. These scores are validated for a certain period after ICU admission and for a certain patient population but not for this specific selection of transferred patients $[25,26]$. The transfer process itself may even influence the severity score. In the paediatric literature there is evidence of changing severity scores due to stabilization and transfer by specialized retrieval teams $[27,28]$. Although some scores, such as Acute Physiology and Chronic Health Evaluation III and Intensive Care National Audit and Research Centre score, adjust for admission source $[29,30]$, lead time bias as well as other undefined influences are still thought to explain differences in severity scores after transfer [25,31]. Therefore, it is not possible to make realistic outcome comparisons between transferred and non-transferred patients by using our standard scoring systems [32,33]. Research based on scoring systems that are not validated for this specific patient population will not lead to reliable conclusions.
Severity scores as a guide for triage for the necessary level of expertise of a transfer team has been investigated in two small studies [34,35]. Although this score did seem to be very useful in discriminating between highrisk and low-risk patients, the relevance to the critically ill is doubtful since only a few of the low-risk patients were actually admitted to an ICU. Moreover, since specialized retrieval teams seem to transfer sicker patients with fewer incidents [36], scoring systems may only be of value in predicting the risk of non-expert transfers [37].

Reported studies have typically a case-series or beforeand-after design while randomized controlled blinded trials are very scarce. With the inherent limitations of definitions and severity scoring systems and the complex organization, high-level evidence will still remain scarce for a long period. We have to realize this when evaluating the present literature and guidelines.

\section{Incident prevention}

By definition, critically ill patients are prone to changes in their condition even without being transported. The goal during every transport should be the continuation of high-quality ICU care, while preventing deterioration or incidents. Incidents may be divided into medical and technical incidents (Table 1). Medical adverse events are most often cardiovascular or respiratory events. The most common cardiovascular events are hyper- and hypotension, brady- and tachycardias, and arrhythmias, with a reported incidence varying from $6 \%$ to $24 \%$. Respiratory events are most often inadequate ventilation or oxygen desaturation with reported incidences ranging from 0 to $15 \%[5,19,23,36]$.

Equipment failure or technical problems are common and may account for $46 \%$ of all incidents [38-40]. Reported incidences vary from $9 \%$ to $36 \%$ [23,36,41]. Transfer by specialized retrieval teams seems to lower the incidence of technical failure [41], emphasizing the need for training and technical understanding of the equipment used [22] and the need for standardized

\section{Table 1 Incidents}

\begin{tabular}{|c|c|c|c|}
\hline & \multicolumn{2}{|l|}{ Medical } & \multirow[b]{2}{*}{ Technical } \\
\hline & Cardiovascular & Respiratory & \\
\hline Incidence & $6-24 \%$ & $0-15 \%$ & $9-36 \%$ \\
\hline \multirow[t]{4}{*}{$\begin{array}{l}\text { Common } \\
\text { events }\end{array}$} & Hypo-/hypertension & $\begin{array}{l}\text { Inadequate } \\
\text { ventilation }\end{array}$ & Power failure \\
\hline & Brady-/tachycardias & $\begin{array}{l}\text { Oxygen } \\
\text { desaturation }\end{array}$ & $\begin{array}{l}\text { Gas supply } \\
\text { problems }\end{array}$ \\
\hline & Arrhythmias & & $\begin{array}{l}\text { Missing } \\
\text { equipment }\end{array}$ \\
\hline & & & $\begin{array}{l}\text { Damaged } \\
\text { equipment }\end{array}$ \\
\hline
\end{tabular}

Up to $31 \%$ of incidents are classified as significant; up to $79 \%$ require an intervention; 52 to $91 \%$ are preventable. 
transfer equipment [20]. Of all incidents, up to $31 \%$ are classified as significant $[4,38]$ and up to $79 \%$ require an intervention [40].

Strikingly, most incidents seem to be preventable. One study reported that up to $91 \%$ of incidents were preventable [39]. Factors associated with fewer incidents are good crew skills/teamwork, checking equipment and the patient, patient monitors and good interpersonal communication [39].

\section{Specialized retrieval teams versus standard transportation}

In 1987 Pearl and colleagues [42] argued that the critical ill transport team is incomplete without a transport physician, just as an ICU would be incomplete without an intensivist. Since it is desirable to maintain an equivalent level of intensive care during transfer to that before transfer, it seems reasonable that a physician should accompany the patient. However, there are no published prospective randomized studies comparing a physicianstaffed transport team with a non-physician-staffed team. The available evidence is of a lower level and mainly from paediatric care. Comparing 130 paediatric transports, 8\% of all problems occurred with a specialized physicianstaffed transport team, $20 \%$ occurred with a nonphysician-staffed specialized team and $72 \%$ occurred with escorts without transport training, even though there were far more specialized physician transfers (54) than non-physician (44) and untrained escorts (32) [43]. Another study comparing transfer by air and ground transportation found significantly better protocol adherence when patients were transferred by air, which according to the authors was the result of the advanced trauma training of the attending flight physician [44]. Vos and colleagues compared 137 transports performed by referral specialists (mainly paediatricians) with 112 transports performed by a specialized retrieval team (mainly paediatric intensivists). Transfers performed by the referral physicians were associated with a higher incidence of complications, unavailability of equipment, and more frequent requirement for acute interventions upon arrival [45]. This was concordant with an earlier study by Bellingan and colleagues [46] that showed a reduction in acute physiology disturbances and a reduced mortality in critically ill patients transferred by a specialized retrieval team.

Nonetheless, a review published in 2006 concluded that insufficient data existed to determine whether the use of specialist transport personnel improves patient outcome. Of 39 publications, 33 were excluded because there was either no control group or an unsuitable control group. In only one study, intervention and control groups were matched [47]. No study was prospective, randomized and controlled. In recent years two before and after studies, performed in the same region, showed that the establishment of a specialized retrieval team was associated with a decline in adverse events (from 34 to $12.5 \%)[19,36]$. In the first phase critically ill patients were transported by standard ambulances with or without referral specialist accompaniment, whereas in the second phase a specialized retrieval team comprising an intensivist and an ICU nurse performed the transfers. This specialized team appeared to be able to transfer sicker patients with fewer and less severe adverse events. In 2011 Kue and colleagues [48] presented similar findings in a preliminary report showing that the introduction of a specialized transport team for intrahospital transfers reduced the incidence of adverse events from 8 to $1.7 \%$. In a large observational study of children admitted to 29 paediatric ICUs, Ramnarayan and colleagues [49] found that transfer by a specialized transfer team was associated with an odds ratio of mortality of 0.58 (95\% confidence interval 0.39 to 0.87 ).

The obvious advantage of a specialized retrieval team is that it is more familiar with transport-specific procedures and equipment, although several other advantages of retrieval teams have also been proposed. Britto and colleagues [28] concluded that retrieval teams are better able to stabilize the patient prior to the transfer and Iwashyna [50] also argued that front-end discontinuity would be better addressed by an expert transport team.

A retrieval team may also better deal with logistic problems. It may be very difficult to maintain a sufficient amount of trained personnel in all hospitals, especially in the smaller ones. Establishing centrally located retrieval teams might then be a better option [51,52]. Moreover, these retrieval teams can also be deployed in remote and rural area health facilities to provide critical care skills to resuscitate and stabilize patients, before transferring them $[53,54]$.

Although unequivocal evidence is not (yet) available, expert opinion is clear: critically ill patients should preferably be transferred by a specialized retrieval team. In a survey among the medical heads of all ICUs in the Netherlands published in 2008, escorting personnel and transport facilities were rated as the most important factors in considering whether or not a transfer would be feasible [55]. It is no surprise, therefore, that most intensive care societies recommend the use of specialized retrieval teams [56-58] or at least the use of specific trained personnel $[14,15]$.

\section{Transport mode}

Road ambulances, fixed wing aircraft and helicopters are all used for interhospital transfers. Many studies, particularly those involving secondary transfer of patients who have suffered traumatic injuries, have found that air transport was time saving [59-62]. These savings can, 
however, easily be offset by mobilization time (fixed wing or rotary wing aircraft are not always immediately available) and by requirement for additional ground transport between landing site and hospital.

In these studies, ground transports in the control groups were performed by local ambulance services. If ground transfers are performed by centrally located specialized transfer teams, overall transfer times may increase, since these teams must first travel from their base to the referring hospital. For this reason, Safford and colleagues [62] compared transfer times between helicopter and ground transports with specialized ambulance teams, stationed at four different bases. The time benefit for air transport was only 27 minutes.

There are no prospective randomized controlled trials showing that the (modest) reduction in transport time with air transport influences patient outcome. In 2011, a retrospective study in the United States compared interhospital transfer by helicopter and road ambulance of almost 75,000 trauma patients [60]. Helicopter transfer was only a predictor of survival for the severely injured those with an injury severity score of $>15$ (odds ratio 1.09). However, helicopter crews are well trained medical teams, whereas ambulance crews sometimes lack essential critical care experience. This could explain the survival benefit and is a potential source of bias in this study. Borst and colleagues [61] recently compared outcome among almost 4,000 patients transferred by helicopter or by specialized acute life support road ambulance. With equivalent crew experience mortality rates were comparable.

It appears then that transfer mode does not affect outcome, or that units are not transferring the appropriate patients by air. Walcott and colleagues [63] found a relatively long interval between arrival and intervention in patients transferred for neurosurgical evaluation. They concluded that triage to helicopter transport was inappropriate. This study emphasizes the importance of triage for air transport prioritizing the patient that will most likely benefit from a reduced transport time. Other factors which should be taken into account are the additional costs of air transport [62], the potential risk, especially for rotary wing aircrafts, the confined space despite the need for ongoing intensive care, the adverse effects of noise and vibration on patient physiology, equipment and communication, long mobilization times and influence of weather conditions [15]. Conversely, road transport has the advantage of lower overall costs, rapid mobilization time, fewer limitations by weather conditions, less potential for physiological disturbance and easier patient monitoring and handling [15]. It has been advised to consider helicopters for transfer distances above $80 \mathrm{~km}$ (50 miles) and fixed wing aircraft for distances above $240 \mathrm{~km}$ (150 miles) but the choice for the individual patient should be based on clinical judgement $[15,64,65]$.

\section{Preparation}

The key to successful transport of the critically ill patient is stabilization before transport [42]. Since up to $91 \%$ of incidents are preventable [39], often by better preparation, it is no surprise that the importance of assessing, resuscitating and stabilizing a patient before transport is still emphasized $[14,66]$.

Of course, these interventions take time to perform, but time spent undertaking intensive care interventions at the referring hospital does not worsen patient outcome [67]. These interventions have even been associated with a shorter length of hospital stay [68].

\section{Equipment}

Over the years, multiple recommendations for minimum transfer equipment requirements have been made $[11,14,15,42,69]$. These focus not only on the continuation of normal critical care (like monitoring, ventilation, administering medication), but also on transfer-specific items (gas supply, batteries) and incident management (defibrillator, chest tubes). In general, an ICU monitor able to display electrocardiography, several pressure curves, capnography and oxygen saturation, a ventilator (preferably an ICU ventilator), airway management tools, arterial and central venous lines, and various medications are advised.

Equipment should be properly mounted in accordance with government regulations. Transfer trolleys should carry all the equipment, such as monitors, syringe pumps, ventilators, suction devices, defibrillator and gas cylinders. For safety reasons, this equipment should be mounted below the level of the patient. Battery life of all electronic devices should be at least several hours and battery life expectancy should be displayed. Of course all equipment must be lightweight and suitable for transfer conditions.

These types of transfer trolleys are usually bigger than standard ambulance stretchers, but during transfer the critically ill patient must be accessible from all sides. Therefore, these patients are commonly transferred in oversized, sometimes specially designed ambulances.

\section{Training}

No studies have evaluated the effect of specific transfer training on outcome. However, since evidence shows that training for relatively simple procedures leads to quality improvement [70,71], it seems logical this applies also to more complex procedures such as transfer of critically ill patients. Transfer teams should be trained before taking responsibility for patient care during transport [22] and a significant determinant of quality of care during transport is the training of the attendant [37]. 
However, surveys continue to demonstrate a lack of formal training in transfer medicine [72,73].

Although local training initiatives have been described [74,75], intensive care societies have not implemented national training programmes. However, they all agree on the importance of specific transfer training for the transport team $[14,15,56,58,76,77]$.

\section{Organizational and legal aspects}

The decision to transfer a patient to another hospital must be made by the responsible consultant, in conjunction with consultant colleagues from relevant specialties in both the referring and receiving hospitals [15]. Ideally, the most appropriate receiving hospital is chosen and the patient or relatives agree with the transfer. Unfortunately, this is not always the case. Stakeholders do not always agree on the reasons for critical care transfers [78] and the most appropriate receiving hospital is not always chosen as the destination [79]. In the United Kingdom critical care networks have been established to improve this and to facilitate and organise transfers. Each network has a lead clinician and manager whose responsibilities include the development of referral pathways and transfer protocols [15]. Moreover, all acute hospitals must have systems and resources in place to resuscitate, stabilise and transport critically ill patients when required. They must have nominated a lead consultant for critical care transfers with responsibility for guidelines training and equipment provision [15]. The situation in the Netherlands is similar to that in the United Kingdom. All hospitals are expected to be able to transfer a high urgency critically ill patient using their own personnel. If time is not a critical factor, however, ICU patients should be transferred by a specialized retrieval team [80]. Interhospital transfer in Australia and New Zealand is arranged the same way as in the Netherlands. Transport of the critically ill patient has to be executed by a specialized retrieval team, including a medical practitioner. In the United States the situation differs. Due to insufficient regulatory control, these transfers are not so well organized [81]. Distribution of critical transfer teams, response time and transfer team composition differ around the country. In fact most often the teams consist of a nurse, paramedic and driver/pilot, although specially trained retrieval teams do exist [81]. In Canada, critical transfer teams often also operate without a physician. However, involved paramedics are well trained, so-called critical care paramedics, experienced in emergency, critical care and transport medicine.

In our opinion, a physician, preferably an intensivist, skilled and trained in the care of critically ill patients during transfer, should accompany the patient and be responsible for the care of the patient during the transfer. Therefore, although referring and receiving staff may agree on the transfer, the accompanying physician should be responsible for the final decision whether the patient is transferrable or not, and for treatment during the transport.

The moment at which responsibility transfers from one team to another should be clear to all involved, and should be stated in a regional or national transport protocol. A formal handover from referring doctor to retrieval doctor and from the latter to the receiving physician is therefore essential.

Since a transfer is a continuation of a patient's treatment and since it is also a situation prone to incidents, it is of the utmost importance to document the transfer process. The clinical record should document the patient's clinical status before, during and after transport, relevant medical conditions, environmental factors and therapy given. Moreover, organisations involved in medical transport should have an effective quality management system that can monitor and audit performance and make recommendations for appropriate improvements $[15,56]$.

\section{Recommendations for the future}

Further study of interhospital transfers is necessary but challenging for several reasons.

First, transfer-related incidents should be defined because the reported rates are partially a result of different definitions. Second, we have to agree on how transfers should be assessed. Long-term endpoints such as length of stay or mortality are probably difficult to evaluate and are of questionable relevance, since a transfer generally covers a small portion of the total ICU treatment. Changes in vital parameters just before and after transfer might be more reasonable, but then definitions or cut off points should be agreed. Stabilization prior to the transfer by the transfer team should also be taken into account. Third, case mix variation is difficult to control

\section{Table 2 Recommendations for the transfer of the} critically ill

\begin{tabular}{l} 
Recommendations and opinions \\
- Critically ill patients should be transferred by a specialized retrieval team \\
- Intensive care should not be interrupted by transportation of the patient \\
- Specialized retrieval teams should receive transfer training \\
- Specific training programmes should be developed \\
- Specialized retrieval teams should be staffed by a physician, \\
preferably an intensivist and an ICU nurse \\
- The accompanying physician makes the final decision whether the \\
- - Experient is transferrable and which treatment is given during the transport \\
- Transfer organisations should have a quality management system \\
- Incident reporting should be standardized and mandatory \\
- Equipment used should conform with both ICU and transfer standards \\
- Adults can learn from children (in the organization of transport) \\
\hline
\end{tabular}


for since risk scores have not been developed for secondary transfers. Fourth, results may be influenced by different characteristics of specialized retrieval teams, such as team composition, whether or not a team received specific training and the kind of equipment used. It might be impossible to investigate the effect of all these characteristics separately. Fifth, although sicker patients are more likely to deteriorate during transfer [4], and thus may benefit more from a specialized transfer than less sick patients, we still have to define which groups of patients should be transferred by specialized retrieval teams. Sixth, in some countries it is already standard procedure to transfer the critically ill with a specialized transfer team, which may jeopardize further randomized controlled trials.

A randomized controlled trial, needed to provide the final evidence, is therefore probably only within reach when it is supported by our specialist societies and conducted in several countries simultaneously. In the interim, and on the basis of the available evidence, we feel that it is warranted to follow the recommendations/opinions listed in Table 2.

\section{Conclusion}

Over the past 40 years the quality of critically ill patient transfers has improved. Currently, it is increasingly accepted that these patients should be transferred by specialized retrieval teams, although definitive evidence is lacking. Further studies are necessary to provide this evidence. In short, we are on our way, but we are not there yet.

\section{Competing interests}

The authors declare that they have no competing interests.

\section{Author details}

'Department of Critical Care, Research Program for Critical Care, Anesthesiology, Per-operative and Emergency medicine (CAPE), University Medical Center Groningen, University of Groningen, Hanzeplein 1, 9700 RB Groningen, The Netherlands. ${ }^{2}$ Department of Anesthesiology, Research Program for Critical Care, Anesthesiology, Per-operative and Emergency medicine (CAPE), University Medical Center Groningen, University of Groningen, Hanzeplein 1, 9700 RB Groningen, The Netherlands. 'Emergency Department, Research Program for Critical Care, Anesthesiology, Per-operative and Emergency medicine (CAPE), University Medical Center Groningen, University of Groningen, Hanzeplein 1, 9700 RB Groningen, The Netherlands.

\section{Published online: 20 February 2015}

\section{References}

1. Wright IH, MCDonald JC, Rogers PN, Ledingham IM. Provision of facilities for secondary transport of seriously ill patients in the United Kingdom. Br Med J (Clin Res Ed). 1988;296:543-5.

2. Iwashyna TJ, Christie JD, Kahn JM, Asch DA. Uncharted paths: hospital networks in critical care. Chest. 2009;135:827-33.

3. Kahn JM, Linde-Zwirble WT, Wunsch H, Barnato AE, Iwashyna TJ, Roberts MS, et al. Potential value of regionalized intensive care for mechanically ventilated medical patients. Am J Respir Crit Care Med. 2008;177:285-91.

4. Kanter RK, Tompkins JM. Adverse events during interhospital transport: physiologic deterioration associated with pretransport severity of illness. Pediatrics. 1989;84:43-8.
5. Wallen E, Venkataraman ST, Grosso MJ, Kiene K, Orr RA. Intrahospital transport of critically ill pediatric patients. Crit Care Med. 1995;23:1588-95.

6. Barry PW, Ralston C. Adverse events occurring during interhospital transfer of the critically ill. Arch Dis Child. 1994;71:8-11.

7. Waddell G, Scott PD, Lees NW, Ledingham IM. Effects of ambulance transport in critically ill patients. BMJ. 1975;1:386-9.

8. Ehrenwerth J, Sorbo S, Hackel A. Transport of critically ill adults. Crit Care Med. 1986;14:543-7.

9. Aitkenhead AR, Willis MI, Barnes WH. An economical mobile intensive care unit. BMJ. 1980;280:1219-21.

10. Day S, McCloskey K, Orr R, Bolte R, Notterman D, Hackel A. Pediatric interhospital critical care transport: consensus of a national leadership conference. Pediatrics. 1991;88:696-704.

11. Guidelines for the transfer of critically ill patients. Guidelines Committee of the American College of Critical Care Medicine; Society of Critical Care Medicine and American Association of Critical-Care Nurses Transfer Guidelines Task Force. Crit Care Med. 1993;21:931-937.

12. Waydhas C. Equipment review: Intrahospital transport of critically ill patients. Crit Care. 1999;3:R83.

13. van Lieshout EJ. Richtlijn voor het transport van Intensive Care patiënten. [Translation: Guideline for the transport of Intensive Care Unit patients]. NVICMon. 2001;5:22-5.

14. Warren J, Fromm RE, Orr RA, Rotello LC, Horst HM, American College of Critical Care Medicine. Guidelines for the inter- and intrahospital transport of critically ill patients. Crit Care Med. 2004;32:256-62.

15. Whiteley S, Macartney I, Mark J, Barratt HS, Binks R. Guidelines for the transport of the critically ill adult (2011). 2011. [http://www.ics.ac.uk/ intensive_care_professional/standards_and_guidelines/transport_of_the_ critically_ill_adult]

16. Kreeftenberg HG, Ligtenberg JJ, Arnold LG, van der Werf TS, Tulleken JE, Zijlstra JG. Condition on arrival of transferred critically ill patients. Neth J Med. 2000;57:180-4.

17. Gray A, Gill S, Airey M, Williams R. Descriptive epidemiology of adult critical care transfers from the emergency department. Emerg Med J. 2003;20:242-6.

18. Vos GD, Nieman FHM, Meurs AMB, van Waardenburg DA, Ramsay G, Donckerwolcke RAMG. Problems in interhospital pediatric intensive care transport in The Netherlands: results from a survey of general pediatricians. Intensive Care Med. 2003;29:1555-9.

19. Ligtenberg JJM, Arnold LG, Stienstra Y, van der Werf TS, Meertens JHJM, Tulleken JE, et al. Quality of interhospital transport of critically ill patients: a prospective audit. Crit Care. 2005;9:R446-51.

20. Haji-Michael P. Critical care transfers - a danger foreseen is half avoided. Crit Care. 2005;9:343-4.

21. Philpot C, Day S, Marcdante K, Gorelick M. Pediatric interhospital transport: diagnostic discordance and hospital mortality. Pediatr Crit Care Med. 2008;9:15-9.

22. Droogh JM, Smit M, Hut J, de Vos R, Ligtenberg JJ, Zijlstra JG. Inter-hospital transport of critically ill patients; expect surprises. Crit Care. 2012;16:R26.

23. Gillman L, Leslie G, Williams T, Fawcett K, Bell R, McGibbon V. Adverse events experienced while transferring the critically ill patient from the emergency department to the intensive care unit. Emerg Med J. 2006;23:858-61.

24. Fan E, MacDonald RD, Adhikari NK, Scales DC, Wax RS, Stewart TE, et al. Outcomes of interfacility critical care adult patient transport: a systematic review. Crit Care. 2006;10:R6.

25. Golestanian E, Scruggs JE, Gangnon RE, Mak RP, Wood KE. Effect of interhospital transfer on resource utilization and outcomes at a tertiary care referral center. Crit Care Med. 2007;35:1470-6.

26. de Lange DW, Dusseljee J, Brinkman S, van Berkel G, van Maanen R, Bosman RJ, et al. Severity of illness and outcome in ICU patients in the Netherlands: results from the NICE registry 2006-2007. Neth J Crit Care. 2009;13:16-22.

27. Tibby SM, Taylor D, Festa M, Hanna S, Hatherill M, Jones G, et al. A comparison of three scoring systems for mortality risk among retrieved intensive care patients. Arch Dis Child. 2002;87:421-5.

28. Britto J, Nadel S, Maconochie I, Levin M, Habibi P. Morbidity and severity of illness during interhospital transfer: impact of a specialised paediatric retrieval team. BMJ. 1995;311:836-9.

29. Knaus WA, Wagner DP, Draper EA, Zimmerman JE, Bergner M, Bastos PG, et al. The APACHE III prognostic system. Risk prediction of hospital mortality for critically ill hospitalized adults. Chest. 1991;100:1619-36.

30. Harrison DA, Parry GJ, Carpenter JR, Short A, Rowan K. A new risk prediction model for critical care: The Intensive Care National Audit \& Research Centre (ICNARC) model. Crit Care Med. 2007;35:1091-8. 
31. Rosenberg AL, Hofer TP, Strachan C, Watts CM, Hayward RA. Accepting critically ill transfer patients: adverse effect on a referral center's outcome and benchmark measures. Ann Intern Med. 2003;138:882-90.

32. Barratt $H$, Harrison DA, Rowan KM, Raine R. Effect of non-clinical interhospital critical care unit to unit transfer of critically ill patients: a propensity-matched cohort analysis. Crit Care. 2012;16:R179.

33. Droogh JM, Renes MH, Ligtenberg JJ, Zijlstra JG. A prolonged ICU stay after interhospital transport? Crit Care. 2012;16:465.

34. Markakis C. Evaluation of a risk score for interhospital transport of critically ill patients. Emerg Med J. 2006;23:313-7.

35. Etxebarría MJ, Serrano S, Ribó DR, Cía MT, Olaz F, López J. Prospective application of risk scores in the interhospital transport of patients. Eur J Emerg Med. 1998;5:13-7

36. Wiegersma JS, Droogh JM, Zijlstra JG, Fokkema J, Ligtenberg JJ. Quality of interhospital transport of the critically ill: impact of a mobile intensive care unit with a specialized retrieval team. Crit Care. 2011;15:1122-5.

37. Bion JF, Manji M. Transporting critically ill patients. Intensive Care Med. 1995;21:781-3

38. Beckmann U, Gillies DM, Berenholtz SM, Wu AW, Pronovost P. Incidents relating to the intra-hospital transfer of critically ill patients: an analysis of the reports submitted to the Australian Incident Monitoring Study in Intensive Care. Intensive Care Med. 2004;30:1579-85.

39. Flabouris A, Runciman WB, Levings B. Incidents during out-of-hospital patient transportation. Anaesth Intensive Care. 2006;34:228-36.

40. Papson JPN, Russell KL, Taylor DM. Unexpected events during the intrahospital transport of critically ill patients. Acad Emerg Med. 2007;14:574-7.

41. Hatherill M, Waggie Z, Reynolds L, Argent A. Transport of critically ill children in a resource-limited setting. Intensive Care Med. 2003;29:1547-54.

42. Pearl RG, Mihm FG, Rosenthal MH. Care of the adult patient during transport. Int Anesthesiol Clin. 1987;25:43-75

43. Macnab AJ. Optimal escort for interhospital transport of pediatric emergencies. J Trauma. 1991;31:205-9.

44. McCrum ML, McKee J, Lai M, Staples J, Switzer N, Widder SL. ATLS adherence in the transfer of rural trauma patients to a level I facility. Injury. 2012;44:1241-5.

45. Vos GD, Nissen AC, Nieman FH, Meurs MMB, van Waardenburg DA, Ramsay $G$, et al. Comparison of interhospital pediatric intensive care transport accompanied by a referring specialist or a specialist retrieval team. Intensive Care Med. 2004;30:302-8.

46. Bellingan G, Olivier T, Batson S, Webb A. Comparison of a specialist retrieval team with current United Kingdom practice for the transport of critically ill patients. Intensive Care Med. 2000;26:740-4.

47. Belway D, Henderson W, Keenan SP, Levy AR, Dodek PM. Do specialist transport personnel improve hospital outcome in critically ill patients transferred to higher centers? A systematic review. J Crit Care. 2006;21:8-17.

48. Kue R, Brown P, Ness C, Scheulen J. Adverse clinical events during intrahospital transport by a specialized team: a preliminary report. Am J Crit Care. 2011:20:153-61.

49. Ramnarayan P, Thiru K, Parslow RC, Harrison DA, Draper ES, Rowan KM Effect of specialist retrieval teams on outcomes in children admitted to paediatric intensive care units in England and Wales: a retrospective cohort study. Lancet. 2010;376:698-704.

50. Iwashyna TJ. The incomplete infrastructure for interhospital patient transfer Crit Care Med. 2012:40:2470-8.

51. McGinn GH, Mackenzie RE, Donnelly JA, Smith EA, Runcie CJ. Interhospital transfer of the critically ill trauma patient: the potential role of a specialist transport team in a trauma system. J Accid Emerg Med. 1996;13:90-2.

52. Oakley PA. The need for standards for inter-hospital transfer. Anaesthesia. 1994:49:565-6.

53. Inglis A, Daly S. Interhospital patient transfer infrastructure. Crit Care Med. 2013:41:e20-1.

54. Wong K, Levy RD. Interhospital transfers of patients with surgical emergencies: areas for improvement. Aust J Rural Health. 2005;13:290-4.

55. Lieshout EJ, Vos R, Binnekade JM, Haan R, Schultz MJ, Vroom MB. Decision making in interhospital transport of critically ill patients: national questionnaire survey among critical care physicians. Intensive Care Med. 2008:34:1269-73.

56. College of Intensive Care Medicine of Australia and New Zealand, Australian and New Zealand College of Anaesthetists, Australasian College for Emergency Medicine. Minimum Standards for Transport of Critically III Patients. 2013. [http://www.anzca.edu.au/resources/professional-documents/pdfs/ps522013-guidelines-for-transport-of-critically-ill-patients.pdf/view]
57. CBO richtlijn. Organisatie en werkwijze op intensive care-afdelingen voor volwassenen in Nederland. 2006. [http://stibera.nl/Pdf/NVA\%20Richtlijn\% 20Intensive\%20Care\%202006.pdf]

58. PACT module: Patient Transportation. [http://pact.esicm.org]

59. Svenson JE, O'Connor JE, Lindsay MB. Is air transport faster? A comparison of air versus ground transport times for interfacility transfers in a regional referral system. Air Med J. 2006;25:170-2.

60. Brown JB, Stassen NA, Bankey PE, Sangosanya AT, Cheng JD, Gestring ML. Helicopters improve survival in seriously injured patients requiring interfacility transfer for definitive care. J Trauma. 2011;70:310-4.

61. Borst GM, Davies SW, Waibel BH, Leonard KL, Rinehart SM, Newell MA, et al. When birds can't fly. J Trauma Acute Care Surg. 2014;77:331-7.

62. Safford SD, Hayward TZ, Safford KM, Georgiade GS, Rice HE, Skinner MA. A cost and outcomes comparison of a novel integrated pediatric air and ground transportation system. J Am Coll Surg. 2002:195:790-5.

63. Walcott BP, Coumans J-V, Mian MK, Nahed BV, Kahle KT. Interfacility helicopter ambulance transport of neurosurgical patients: observations, utilization, and outcomes from a quaternary level care hospital. PLoS One. 2011;6:e26216.

64. Gray A. Secondary transport of the critically ill and injured adult. Emerg Med J. 2004;21:281-5.

65. Wallace $P$, Ridley $S$. ABC of intensive care: transport of critically ill patients. BMJ. 1999;319:368-71.

66. Shirley PJ, Hearns S. Retrieval medicine: a review and guide for UK practitioners. Part 1: clinical guidelines and evidence base. Emerg Med J. 2006;23:937-42.

67. Borrows EL, Lutman DH, Montgomery MA, Petros AJ, Ramnarayan P. Effect of patient- and team-related factors on stabilization time during pediatric intensive care transport. Pediatr Crit Care Med. 2010;11:451-6.

68. Belway D, Dodek PM, Keenan SP, Norena M, Wong $\mathrm{H}$. The role of transport intervals in outcomes for critically ill patients who are transferred to referral centers. J Crit Care. 2008:23:287-94.

69. Vos GD, Buurman WA, van Waardenburg DA, Visser TPL, Ramsay G, Donckerwolcke RAMG. Interhospital paediatric intensive care transport: a novel transport unit based on a standard ambulance trolley. Eur J Emerg Med. 2003;10:195-9.

70. Britt RC, Novosel TJ, Britt LD, Sullivan M. The impact of central line simulation before the ICU experience. Am J Surg. 2009;197:533-6.

71. Mayo PH, Hegde A, Eisen LA, Kory P, Doelken P. A program to improve the quality of emergency endotracheal intubation. J Intensive Care Med. 2011;26:50-6.

72. Spencer C, Watkinson P, McCluskey A. Training and assessment of competency of trainees in the transfer of critically ill patients. Anaesthesia. 2004;59:1248-9.

73. Cook CJ, Allan C. Are trainees equipped to transfer critically ill patients. JICS. 2008;9:145-7.

74. Cosgrove JF, Kilner AJ, Batchelor AM, Clarke F, Bonner S, Mensah J. Training and assessment of competency in the transfer of critically ill patients. Anaesthesia. 2005;60:413-4

75. Droogh JM, Kruger HL, Ligtenberg JJM, Zijlstra JG. Simulator-based crew resource management training for interhospital transfer of critically ill patients by a mobile ICU. Jt Comm J Qual Patient Saf. 2012;38:554-9.

76. Association of Anaesthetists of Great Britain and Ireland. AAGBI safety guideline. 2009. [http://www.aagbi.org/sites/default/files/interhospital09.pdf]

77. Quenot J-P, Milési C, Cravoisy A, Capellier G, Mimoz O, Fourcade O, et al. Intrahospital transport of critically ill patients (excluding newborns) Recommendations of the Societe de Reanimation de Langue Francaise (SRLF), the Societe Francaise d "Anesthesie et de Reanimation (SFAR), and the Societe Francaise de Medecine d" Urgence (SFMU). Ann Intensive Care. 2012;2:1.

78. Wagner J, Iwashyna TJ, Kahn JM. Reasons underlying interhospital transfers to an academic medical intensive care unit. J Crit Care. 2012;28:202-8.

79. Bosk EA, Veinot T, Iwashyna TJ. Which patients and where: a qualitative study of patient transfers from community hospitals. Med Care. 2011;49:592-8

80. Ministry of Public Health. Temporary guideline coordinating MICU-centers and MICU-transfer. 2007. [http://www.rijksoverheid.nl/documenten-en-publicaties/ kamerstukken/2007/11/05/tijdelijke-regeling-micu-transport.html]

81. Williams KA, Sullivan FM. Critical care transport. R I Med J. 2013;96:39-43. 